\title{
Mitteilung der Schriftleitung
}

Am 30.9.1998 wechselte die Schriftleitung dieser Zeitschrift von Herrn Professor Dr. Dr. h.c. Herbert Hax zu mir. Zugleich schied Herr Professor Dr. Dr. h.c. Rudolf Gümbel aus dem Herausgebergremium aus. Anlaß hierzu war in beiden Fällen die Emeritierung. Schließlich legte zum Jahresende Herr Professor Dr. Erich Frese die Herausgeberschaft nieder, um sich - nach einem runden Geburtstag - in den kommenden Jahren intensiv neuen Forschungsprojekten widmen zu können. Als neue Herausgeber wurden die Herren Professoren Dr. Sönke Albers, Dr. Günter Franke und Dr. Alfred Wagenhofer gewonnen.

Die Verdienste von Herbert Hax, Rudolf Gümbel und Erich Frese für diese Zeitschrift, und damit für die betriebswirtschaftliche Forschung in Deutschland, sind unschätzbar. 1970 sind Herbert Hax und Rudolf Gümbel - zusammen mit Walther Busse von Colbe, Erwin Grochla, Gert Laßmann, Dieter Schneider und Klaus v. Wysocki - Herausgeber geworden, um Karl Hax in der Schriftleitung und Herausgabe dieser Zeitschrift zu entlasten. 1986 wurde Erich Frese Herausgeber. Sie alle zusammen haben es über drei Jahrzehnte hinweg verstanden, die ZfbF als stark theoriegeprägte und gleichzeitig anwendungsorientierte betriebswirtschaftliche Zeitschrift an eine, wenn nicht die führende Position deutscher Zeitschriften zu bringen.

Unter der fragwürdigen Annahme einer Gleichverteilung von gedruckten Beiträgen allein auf die im Herausgeberkreis befindlichen Hochschullehrer haben Herbert Hax und Rudolf Gümbel von 1970 bis 1998 jeweils rund 160 Aufsätzen den Weg in die ZfbF geebnet. Bei einer angenommenen Ablehnungsquote von zwei Drittel waren das rund 480 Manuskripte, für die jeder Herausgeber verantwortlich zeichnete. Insgesamt hat Herbert Hax als Schriftleiter aber rund 3000 Manuskripte erhalten, begutachtet oder weitergeleitet, ganz zu schweigen von knapp 200 Würdigungen und unzählbaren Rezensionen. Erich Frese hat seit 1993 das Kontaktstudium geleitet und die Schriftleitung hierdurch maßgeblich zusätzlich entlastet.

Die Herausgeber danken Herbert Hax, Rudolf Gümbel und Erich Frese sehr herzlich für die aufwendige und verdienstvolle Arbeit für diese Zeitschrift, für das kollegiale und sehr angenehme Klima in den Herausgebersitzungen und die Gelegenheit, fruchtbar mit ihnen zusammenarbeiten zu können. Die Schriftleitung und die Herausgeber fühlen sich dem über drei Jahrzehnte gewonnenen eindeutigen Profil der ZfbF verpflichtet und setzen alles daran, die führende Position dieser Zeitschrift zu erhalten beziehungsweise auszubauen. Herbert Hax, Rudolf Gümbel und Erich Frese wünschen sie alles erdenklich Gute für den weiteren Lebensweg! 